\title{
Review of smart learning: Patterns and trends in research and practice
}

\author{
Kam Cheong Li, Billy Tak-Ming Wong \\ The Open University of Hong Kong, Hong Kong, China
}

\begin{abstract}
This article presents a review of the literature on smart learning in order to provide a comprehensive overview of its latest developments in research and practice. The review covered 90 studies published from 2010 to 2019, which were collected from three publication databases, namely Web of Science, Scopus and ProQuest. They were analysed for the patterns and trends in terms of publication years, sources of publication, countries or regions of publication, research purposes, research methods, educational levels of the studies, application domains, research issues, research participants, learning devices or tools, learning environments and learning features. Overall, the findings show that increasing global attention was given to smart learning from diverse disciplines and contexts of application. The results also reveal the areas which should be addressed in future work: development of pedagogies which make effective use of smart learning technologies in different learning environments; examination of smart learning to cope with learners' needs in informal contexts; in-depth analysis of how smart learning could be tailored to fit the characteristics of various application domains; and investigation of the views and perceptions of teachers on smart learning technologies, their readiness to use these technologies and their challenges and needs for support.
\end{abstract}

Implications for practice or policy:

- It is important for educators and practitioners to keep abreast of the latest developments in research and practice with regard to smart learning.

- It is important for teachers to understand their role in smart learning practice and the use of smart learning technologies to cope with learner needs.

- It is important for administrators in educational institutions to understand the challenges faced by teachers in smart learning practice and formulate measures to support them.

Keywords: smart learning, smart learning environment, smart education, smart classrooms

\section{Introduction}

Smart learning, or smart education, has been emerging with an increasing amount of research and practice since the 2010s. It is conceptualised as a paradigm of technology-enhanced learning evolving from traditional web-based, mobile and ubiquitous learning (Hwang, 2014) and emphasising technological design (Gros, 2016). Smart learning has been regarded as "a new 21st century educational paradigm that fosters and develops all students to become global leaders by renovating the existing education system, such as educational contents, methods, evaluations, and environments" (Hwang \& Choi, 2016, p. 2).

Despite the concept being relatively new, researchers have highlighted the major features of smart learning. For example, Choi et al. (2016) raised the acquisition of new knowledge "at any time and any place by using smart devices" (p. 2) as a common feature among various definitions of smart learning. Hwang and Choi (2016) defined smart learning with "smart" as an acronym - self-directed, motivated, adaptive, resource-enriched, and technology-embedded. Also, Zhu et al. (2016) summarised the crucial components of smart learning in the literature as its being learner-centric, personalised, adaptive, interactive, collaborative, context-aware and ubiquitous.

Closely related to the notion of smart learning are the environments in which it is practised, which are referred to as smart classrooms and smart learning environments. The former commonly refers to a traditional or physical classroom that integrates advanced technologies to facilitate students' learning and interaction (e.g., Chen et al., 2015; Lui \& Slotta, 2014; MacLeod et al., 2018). The latter can be a physical and/or a virtual learning environment (Kinshuk et al., 2016), which is able to sense and infer, and thus autonomously and actively provide "the necessary learning guidance, hints, supportive tools or learning 
suggestions" (Gros, 2016, p. 4) to learners "in the right place, at the right time and in the right form" (Hwang, 2014, p. 2).

As an emerging mode of learning, smart learning has been of interest to many researchers, and a broad range of initiatives have been carried out. They include various contexts of research and practice, such as research issues, groups of participants, smart devices, learning disciplines and environments. The results have revealed the vast potentials of smart learning, for example, intelligent classroom management (Mahesh et al., 2016), teaching and learning diagnosis (Şahin \& Yurdugül, 2019), personalisation of learning contents (Vesin et al., 2018) and improvement of skills and competence (Huh \& Lee, 2020).

Despite the wide range of related work reported in the literature, previous reviews have not provided a comprehensive overview of smart learning research and practice. Most reviews have focused only on some specific areas of smart learning, such as definitions (Hwang, 2014), research frameworks (Zhu et al., 2016), smart technologies (Yoo et al., 2015) and disciplinary practices (Vasbieva et al., 2018). Given the scattered aspects of smart learning reviewed, it is difficult to obtain a holistic view of the status of development in this area.

This article aims to address the gap in the literature by giving a comprehensive picture of the current development of research and practice in smart learning. It presents a systematic review of the literature on this topic published in the past decade (2010 to 2019). The results of this review show the patterns and recent trends in smart learning research and practice and reveal the need for future work to advance the development. In particular, the review focused on the following research questions:

- What are the patterns of publications on smart learning, in terms of publication year, source and country or region?

- What are the patterns of smart learning research, as regards aspects such as research issues, research methods and research participants?

- What are the patterns of smart learning practice, in terms of aspects such as device or tool, learning environment and purpose?

- What are the trends in smart learning research and practice?

\section{Related studies}

Although there have been a number of review studies on the development of smart learning, only a few of them have aimed to provide an overview of its development. For example, Ha and Kim (2014) reviewed the early work on smart learning and identified the research trends at that time. They pointed out the features of relevant studies, which were mostly associated with mobile learning and the positive findings commonly obtained from the studies. Suwita et al. (2019) focused on the context of massive open online courses to review the factors involved in successful smart learning. From 25 articles, they summarised three major factors related to approaches, technologies and content. Also, Singh and Miah (2020) outlined smart learning literature in terms of five major themes - a cloud-based environment, the Internet of Things, big data, a smart campus and issues (privacy, security and distraction). Overall, reviews of this type have contributed to revealing some aspects of smart learning development but have yet to provide a comprehensive picture of it.

Other review studies usually had more specific foci, many of which have targeted synthesising the relevant concepts to generate a definition or framework of smart learning. For example, Hwang (2014) proposed a definition and a number of criteria of smart learning environments from the perspective of context-aware ubiquitous learning, based on which Hwang presented a framework to guide the design and development of smart learning environments. Liu et al. (2016) reviewed the opinions of stakeholders on smart cities and smart learning from multicultural perspectives, highlighting the need to consider the cultural context in the planning of a smart school. Zhu et al. (2016) addressed the pedagogical aspect and proposed a four-tier framework of smart pedagogies, which covered what they referred to as mass-based generative learning, individual-based personalised learning, group-based collaborative learning and class-based differentiated instruction. Heinemann and Uskov (2018) conducted a systematic creative analysis of the literature on smart learning and presented a smart maturity model as a guide for a traditional university to progress towards various levels of smartness of a smart university. In addition, Cebrian et al. (2020) explored the 
relationships between smart classrooms and education for sustainable development in order to identify how the characteristics of smart classrooms can contribute to its effective implementation.

A smart learning environment or technology has been another major area in the review studies. For example, Yoo et al. (2015) focused on the design and development of educational dashboards in smart learning, covering their educational data mining and visualisation techniques. They also proposed an evaluation framework for assessing the dashboard functions with regard to pedagogical and visual aspects. Kearney et al. (2019) reviewed the nature of smart pedagogies and their use in mobile learning activities in order to examine the support for teachers to implement "feasible disruptions" (p. 139). Saini and Goel (2019) presented a survey of smart classroom technologies, ranging from those used for content preparation, presentation and dissemination to those for smart interaction and engagement, as well as feedback and assessment. Also, Kassab and Mazzara (2020) summarised ways of incorporating the Internet of Things into education and discussed relevant requirements, such as security, scalability and humanisation.

A review area which has received more attention in recent years is stakeholders' perspectives in disciplinary practices. Huh (2018) addressed the key factors for the success of an English language classroo where the supportive conditions for learners, teachers and administrators were emphasised. Vasbieva et al. (2018) investigated the roles of English language teachers in a smart learning environment. They highlighted the need for a sustainable transformation in teachers' roles, so that they become facilitators, collaborators, technicians, managers and researchers, in addition to their traditional roles as course designers and developers. Rao (2019) examined the awareness of university staff and students of smart learning resources available for the mechanical engineering discipline.

There are a number of limitations in these reviews for presenting the current status and future directions of smart learning research and practice. In particular, most of the reviews have focused only on a single perspective, such as technology and disciplinary practice. Besides, some reviews have been devised with specific objectives, for example, as the basis for formulating a framework for the development of smart learning systems (Singh \& Miah, 2020) or providing teacher support (Vasbieva et al., 2018). In addition, Saini and Goel (2019) noted that the areas covered in these reviews can hardly provide a comprehensive view of the state-of-the-art of smart learning. To address the gap in the literature, this article presents a comprehensive review of the smart learning literature on both research and practice.

\section{Research method}

\section{Data sources}

Relevant articles collected for the review were searched using three commonly used publication databases, namely Web of Science, Scopus and ProQuest. The Boolean expression of keywords ("smart learning" OR "smart education" OR "smart classroom") was used for the search. The time range was confined to the years 2010 to 2019. The document type was limited to "Article" in Web of Science and Scopus and "Scholarly Journal" in ProQuest. The initial search results consisted of 93 articles from Web of Science, 237 articles from Scopus and 635 articles from ProQuest, that is, 965 articles in total.

The 965 articles were further checked against a set of inclusion criteria to sort out the appropriate ones for review. The inclusion criteria for an article were that it focused on smart learning; was written in English; and was available in full text. Articles that failed to meet any of these criteria were eliminated. As a result, the number of articles was reduced to 27 from Web of Science, 53 from Scopus and 39 from ProQuest. After excluding 29 articles which overlapped, 90 articles were finally selected for analysis. This article search and selection approach has been commonly adopted in other systemic literature reviews (e.g., Li \& Wong, 2020a; Malik et al., 2019; Vlachopoulos \& Makri, 2017). The procedures for article search and selection are presented in Figure 1. 


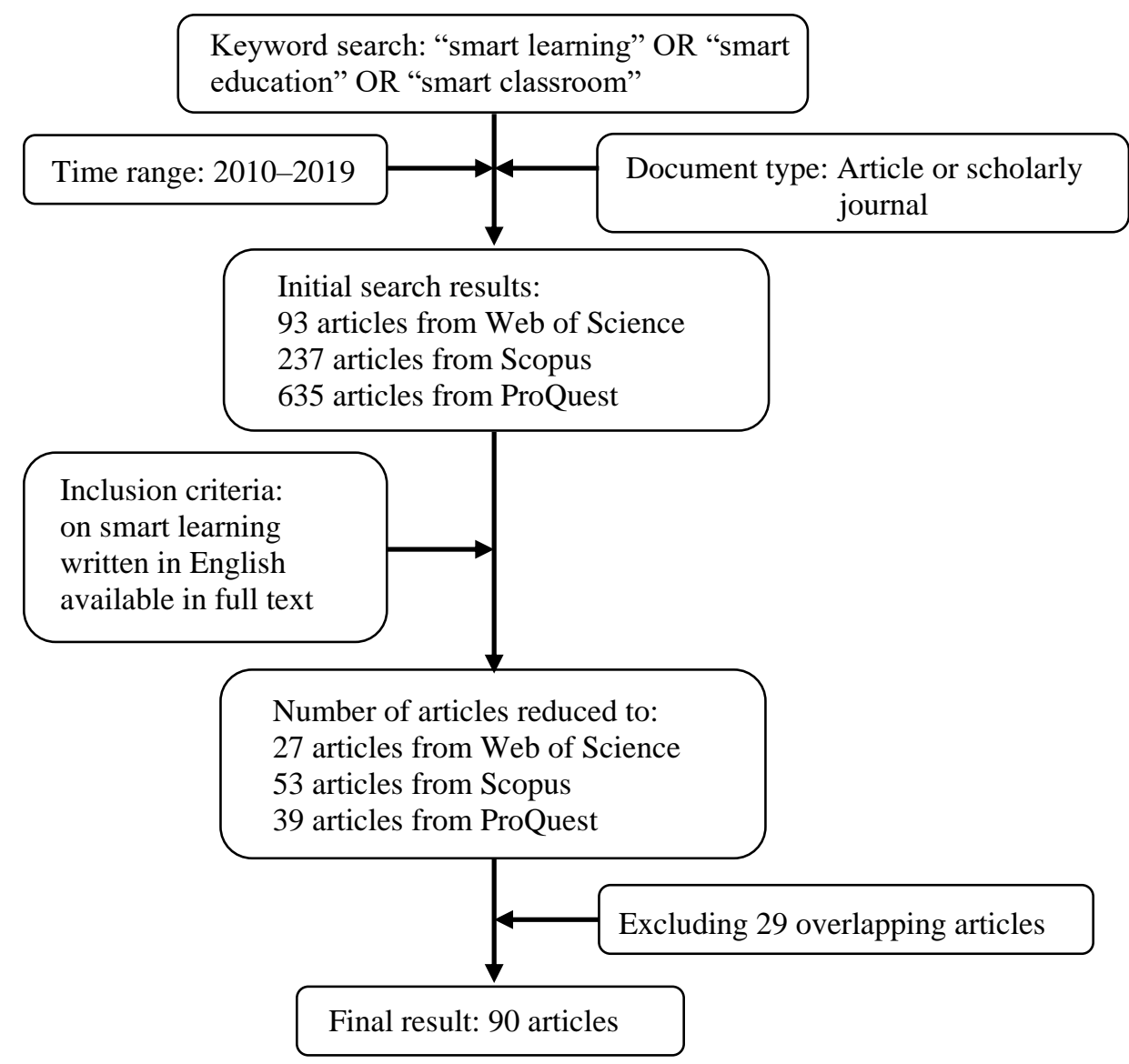

Figure 1. Procedures for search and selection of articles

\section{Data coding and categorisation}

In this review, the categories for analysing the collected articles were based on the technology-based learning review framework proposed by Hsu et al. (2012), which includes various dimensions, such as the design of research, the context of the learning practice and the background of the participants. In addition, following the review approach of $\mathrm{Li}$ and Wong (2020b), the general distribution of the articles is also covered to analyse their patterns. Accordingly, the categories for this review consisted of the following:

- Publication years, sources of publication and countries or regions of publication: This covers the general information in the articles. The sources of publication refer to the journals in which the articles were published. The categorisation of information is based on the approach adopted in $\mathrm{Li}$ and Wong (2020b).

- Research purposes: The categorisation of research purposes was adapted from Tu and Hwang (2018). In this review, the categories consist of literature review and trend analysis; developing a framework in relation to smart learning; designing a smart learning system, service or tool; designing pedagogies or learning activities for smart learning; evaluating the effectiveness or impact of smart learning; and investigating stakeholders' perceptions or experiences.

- Research methods: The categories proposed by McMillan and Schumacher (2006) were used, consisting of quantitative, qualitative and mixed methods.

- Educational levels of studies: The categories of educational levels in Wong et al. (2018) were adapted in this review. They consist of primary, secondary, tertiary and vocation training.

- Application domains: The application domains of smart learning reported in the literature were categorised into science, engineering, computer studies, mathematics, language, education, social studies, physical education, nursing, and others (e.g., tourism, and fire evacuation training). 
- $\quad$ Research issues: The research issues in smart learning studies were adapted from Li and Wong's (2019a) categories. They consist of learning motivation, satisfaction, perceptions, preferences, learning outcomes, learner behaviours and learner experiences.

- Research participants: Based on the categorisation in Tu and Hwang (2018), the research participants were first categorised as students, teachers, school administrators, parents and field experts. The category others was also added to include some special types of participants (e.g., citizens, employees and human resource managers).

- Smart learning devices or tools: They were categorised as smartphones, tablets computers, sensors, interactive whiteboards, projectors, headsets, cameras and augmented reality tools.

- Smart learning environments: The learning environments where smart learning was implemented consist of the classroom, online environment, blended environment, laboratory.

- Smart learning features: The features of smart learning were adapted from the categorisation proposed by Li and Wong (2019a). They consist of rich learning resources, adaptivity, contextawareness, augmented reality, personalised content, personalised learning support, intelligent recommendation, timely intelligent feedback, real-time student feedback, facilitation of interaction, collaborative learning, self-regulated learning, experience-based learning and ubiquitous learning.

Each article was coded by two of the researchers in the project team following the above coding scheme. When any discordant cases were identified, there was a further review and discussion until consent was achieved.

To examine the trends in smart learning research and practice, the coded information on the articles was divided into two periods for comparison, that is, 2010 to 2014 as the first period and 2015 to 2019 as the second period. The changes in the patterns of smart learning were identified to reveal the trends.

\section{Results}

\section{Publication years}

Figure 2 shows the number of articles published from 2010 to 2019. There was an overall trend for an increase in the number of publications on smart learning, particularly since 2014, but from 2015 onwards the number of articles was relatively stable. In terms of the number of publications, the results suggest two major stages of smart learning development in this decade - an emerging and rising stage in 2010 to 2014 and a stable stage in 2015 to 2019.

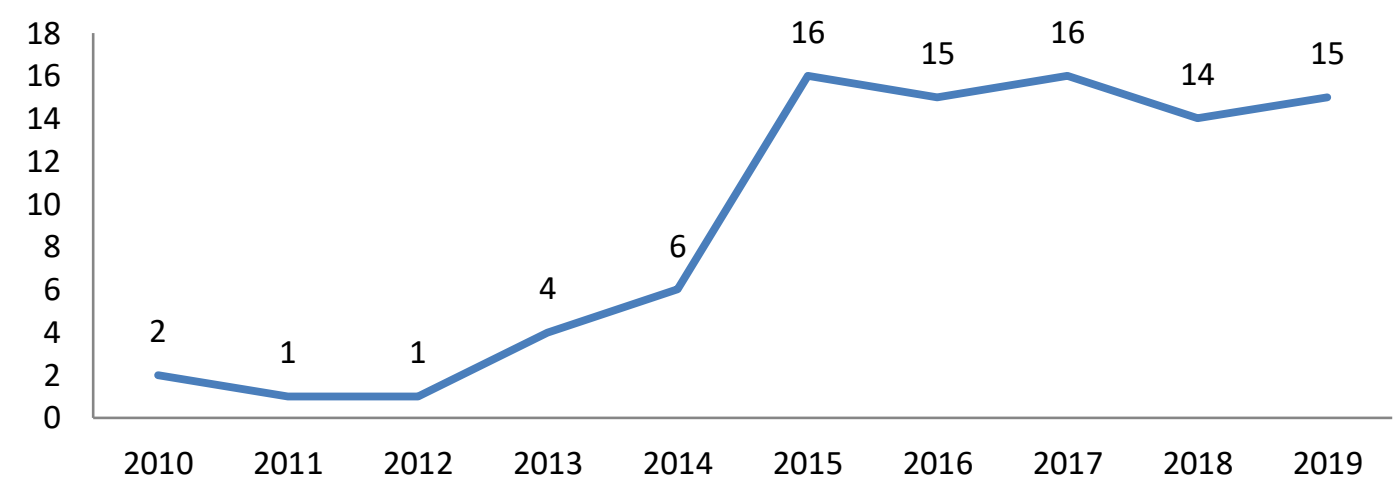

Figure 2. Number of smart learning publications from 2010 to 2019

\section{Sources of publication}

Figure 3 illustrates the sources of the publications in the smart learning literature. The journal Smart Learning Environments emerged as the largest single source, accounting for $21 \%$. This journal, which targets the improvements in teaching and learning through advances in smart learning, was launched in 2014, which helps to explain the surge in smart learning publications in that year. Other articles were published in journals from various fields, such as engineering applications, information technology, and 
educational technology. The others category (33\%) refers to the journals which published only one article in this review. Overall, the results show that smart learning has received attention from scholars and journals from diverse disciplines.

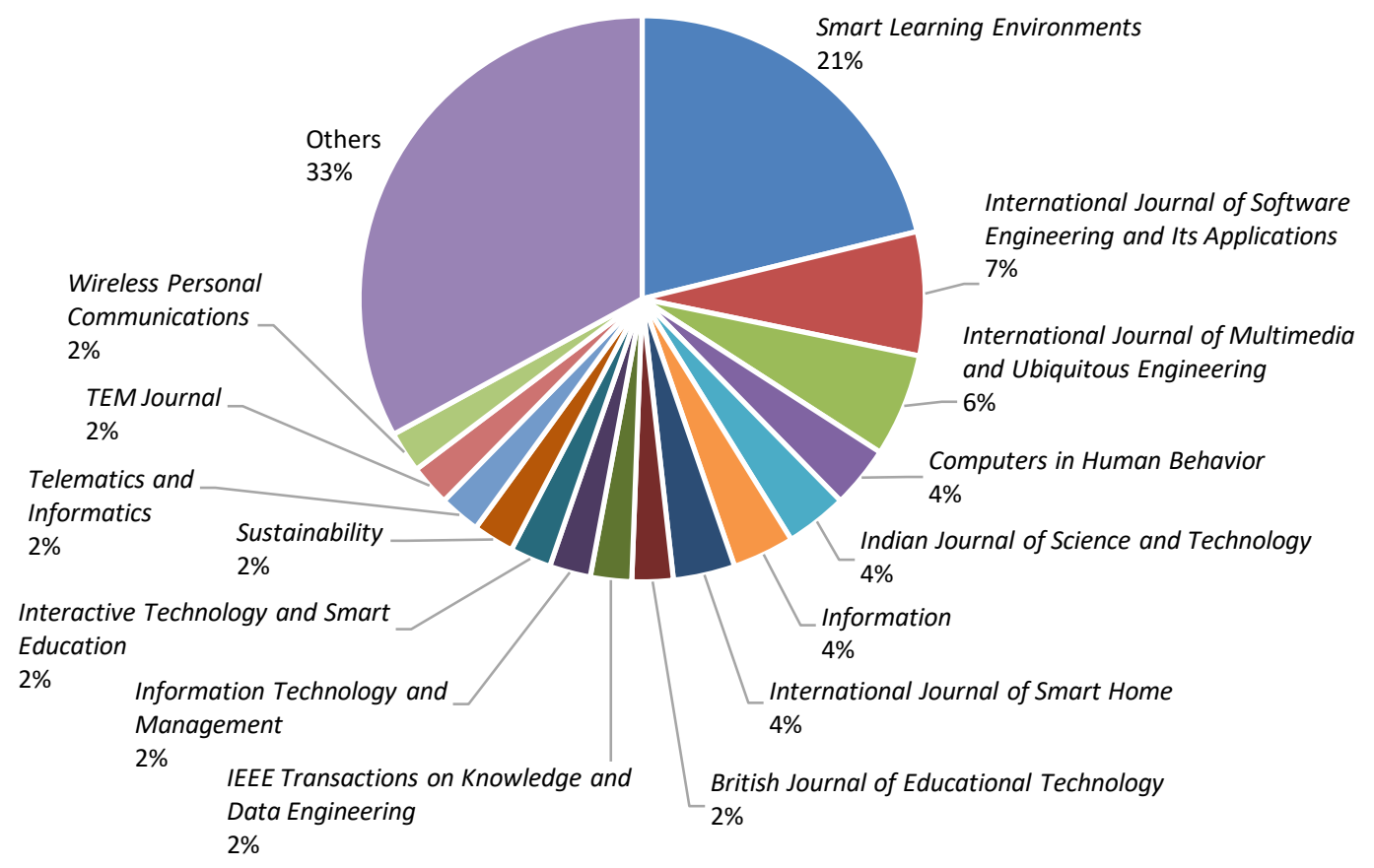

Figure 3. Sources of the smart learning literature

\section{Countries or regions}

Figure 4 presents the location of the authors' institutions. The reviewed articles came from institutions in a total of 34 countries or regions. Institutions in South Korea contributed the largest proportion of the articles (32\%), followed by Mainland China (11\%). The others category refers to the countries or regions with only one institution contributing the articles, consisting of Bulgaria, Ecuador, Egypt, Japan, Jordan, Luxembourg, New Zealand, Russia, Spain and The Netherlands. The results reveal that initiatives on smart learning have spanned the globe, but particularly in institutions in Asia.

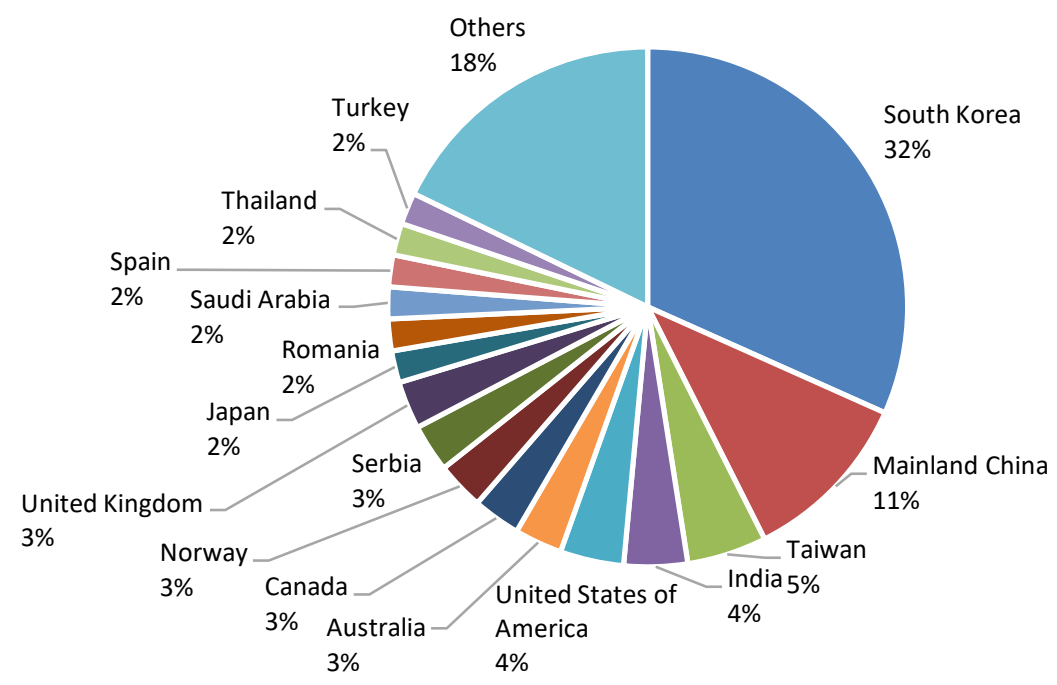

Figure 4. Countries or regions of the smart learning literature 


\section{Research purposes}

Figure 5 shows the research purposes of the smart learning literature in the two periods. In both periods, designing a smart learning system, service or tool was the most frequent research purpose. There was a clear increase in the proportion of articles which focused on developing frameworks in relation to smart learning, which rose from $6 \%$ in the first period to $27 \%$ in the second period, becoming one of the most frequent research purposes. Designing smart learning pedagogies or activities was decreasingly addressed, reducing from $11 \%$ in the first period to only $3 \%$ in the second period.

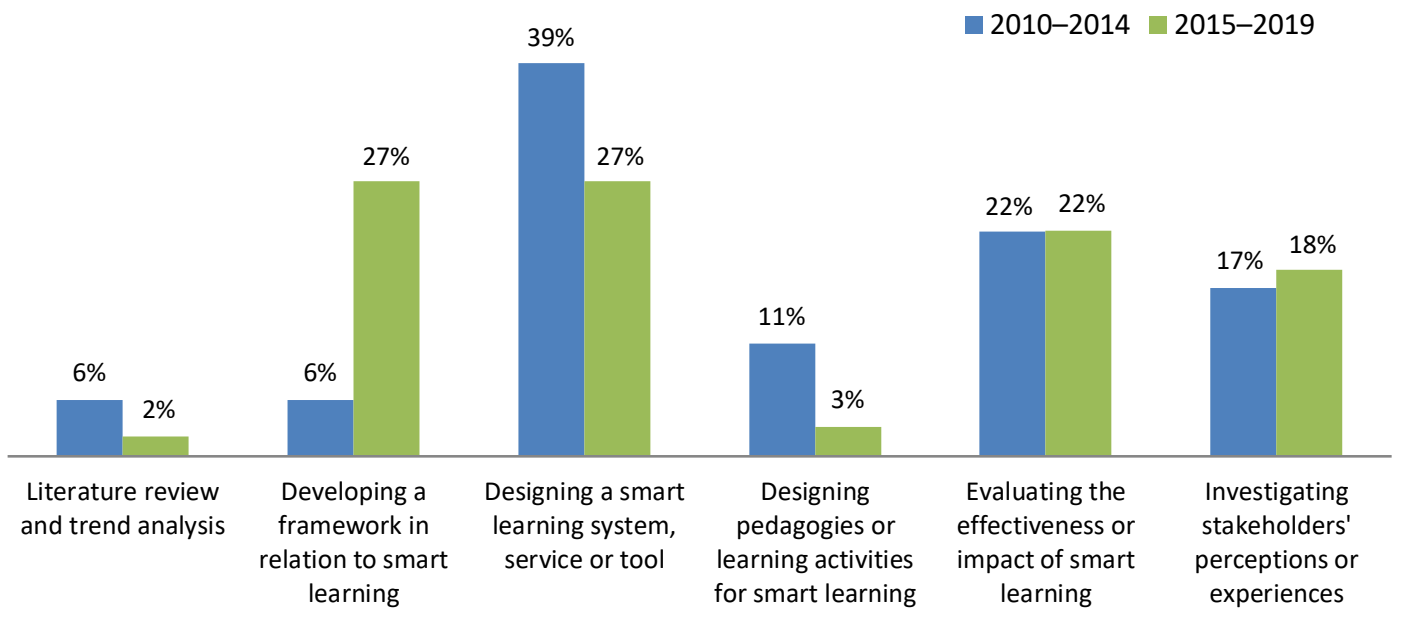

Figure 5. Research purposes of the smart learning studies in the two periods

\section{Research methods}

Figure 6 compares the proportions of research methods in the two periods. Quantitative methods were most commonly used in smart learning research, and their proportions in both periods were similar, that is, about $65 \%$ to $67 \%$. There was also a trend of decreasing use of purely qualitative methods (from $17 \%$ to $11 \%$ ) and increasing use of mixed methods (from $17 \%$ to $24 \%$ ) in the literature.

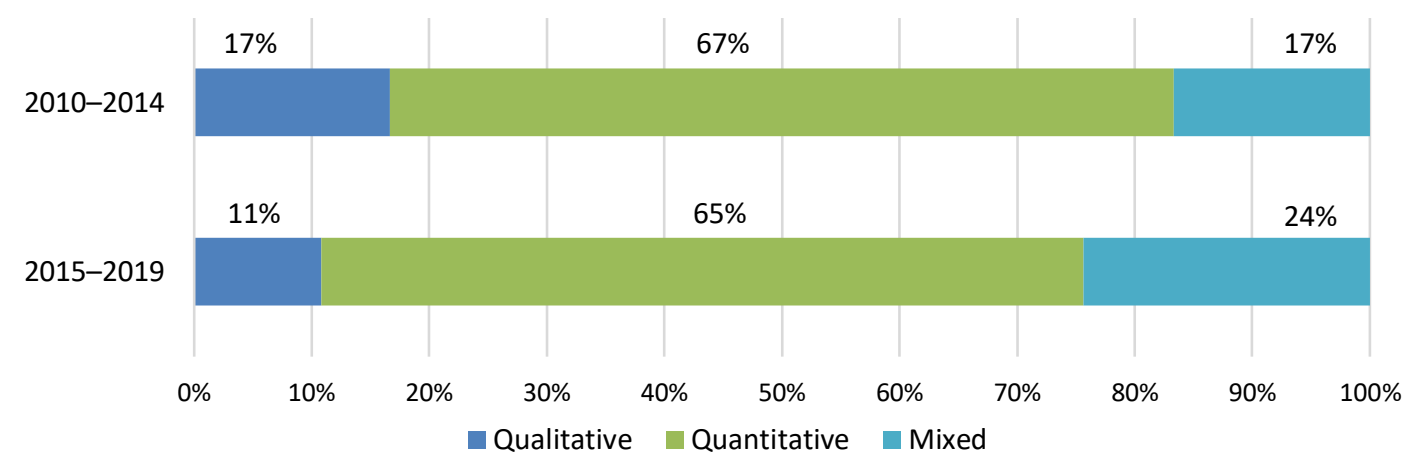

Figure 6. Research methods in the smart learning studies

\section{Educational levels of studies}

Figure 7 shows the educational levels of the smart learning studies in the two periods. It is clear that the studies in the first period addressed only primary, secondary and tertiary education, but in the second period they started to also cover vocational training. There was also a trend of more balanced development of smart learning in various educational levels. The proportions of studies at the primary and tertiary levels shrank from $29 \%$ and $57 \%$ respectively in the first period to $22 \%$ and $44 \%$ respectively in the second period. In contrast, at the secondary level, the proportion increased from $14 \%$ to $25 \%$. 


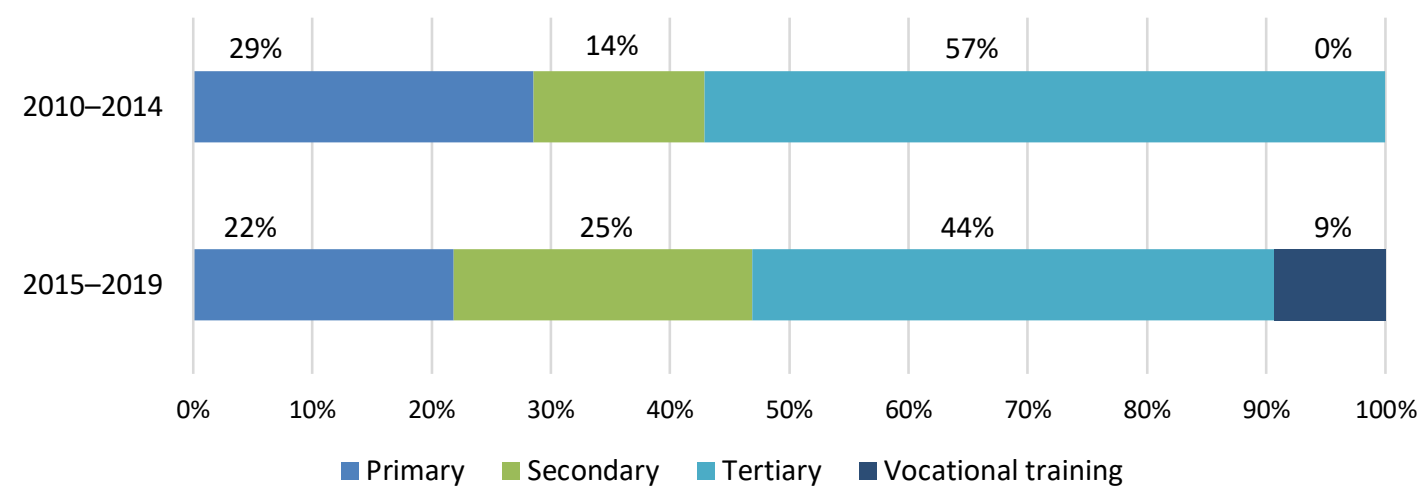

Figure 7. Educational levels of the smart learning studies

\section{Application domains}

Figure 8 presents the application domains of the smart learning studies in the two periods. In both periods, language was the domain with the largest proportion of studies, but in the second period, the proportion in the science domain became as large as that of language. The second period also witnessed a broader range of application domains, many of which emerged in this period, such as engineering, education and mathematics, as well as some unconventional domains, for example, tourism and fire evacuation training (in the others category). The results indicate the growing popularity and applicability of smart learning.

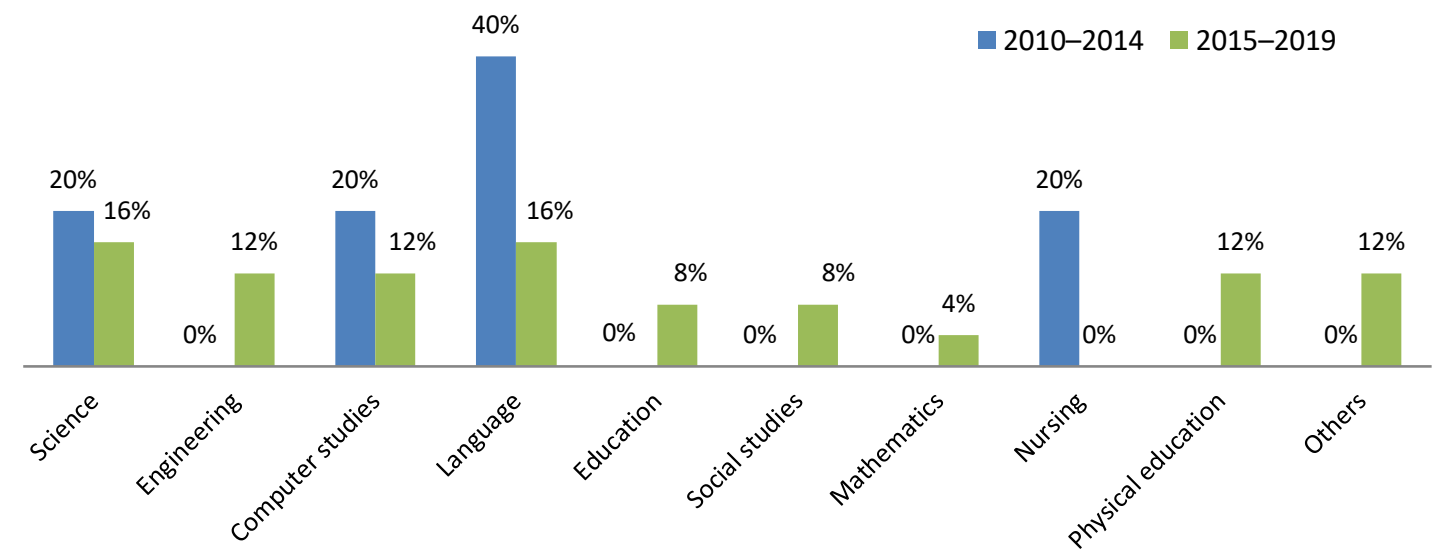

Figure 8. Application domains of the smart learning studies

\section{Research issues}

Figure 9 shows the research issues dealt with in the smart learning studies in the two periods. Notably, studies in the first period focused on perceptions, learning outcomes and learner experiences. In the second period, the proportions of perceptions and learning outcomes reduced but that of learner experiences increased. Also, more research issues were examined in this period, such as satisfaction, learning motivation and preferences. Other than revealing a broader range of issues which received attention, the results also suggest the growing significance of learner experiences in the studies. 


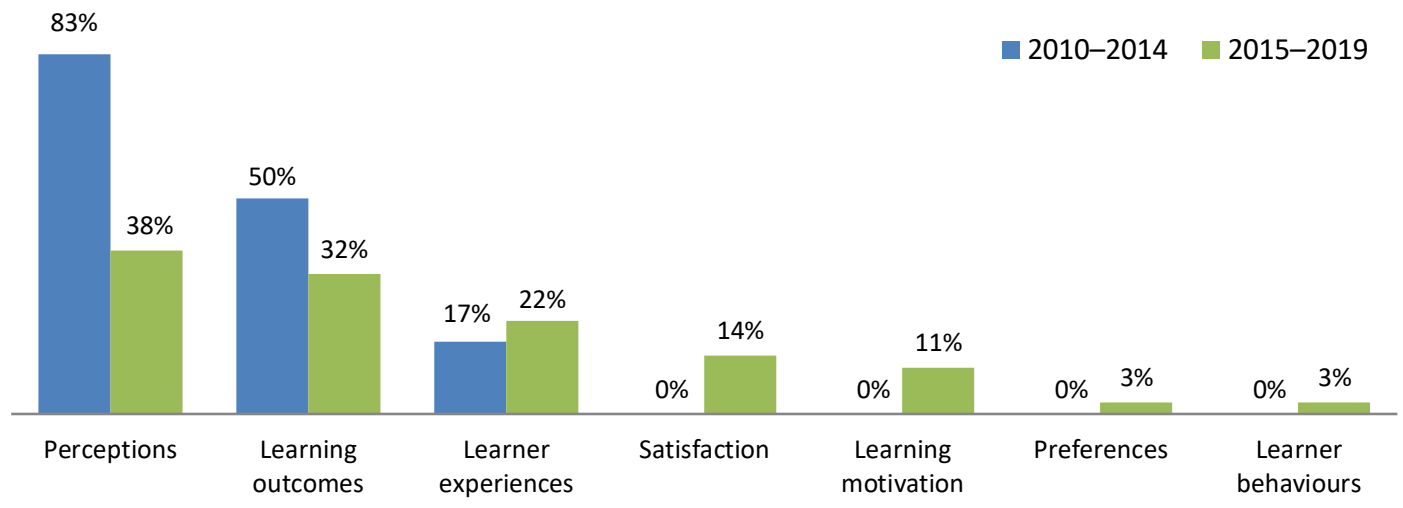

Figure 9. Research issues in the smart learning studies

\section{Research participants}

Figure 10 shows the research participants in the studies in the two periods. The proportion of research participants covered in the studies was largely uneven in both periods, where the majority focused on students (83\% and $73 \%$ in the two periods, respectively). Many more types of stakeholders started to receive attention in the second period, consisting of school administrators, parents, field experts and others (e.g., citizens, employees and human resource managers).

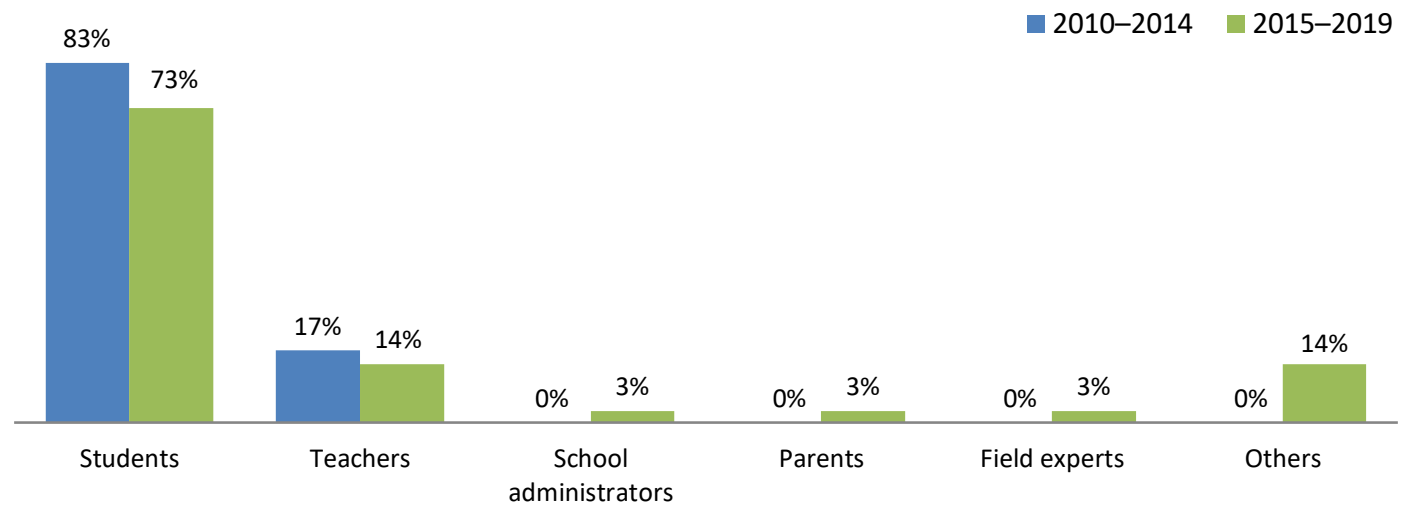

Figure 10. Research participants in the smart learning studies

\section{Smart learning devices or tools}

Figure 11 indicates the changes in the proportion of studies using various smart learning devices or tools. As shown, the use of tablets more than doubled, from $11 \%$ to $25 \%$. Projectors as a type of teaching device seem to have lost their predominance and recorded a substantial decrease from $44 \%$ in the first period to only $9 \%$ in the second period, suggesting that this kind of classroom device has gradually become obsolete. Also, augmented reality tools started to be adopted in the second period, suggesting that augmented reality has become one of the features of smart learning. 


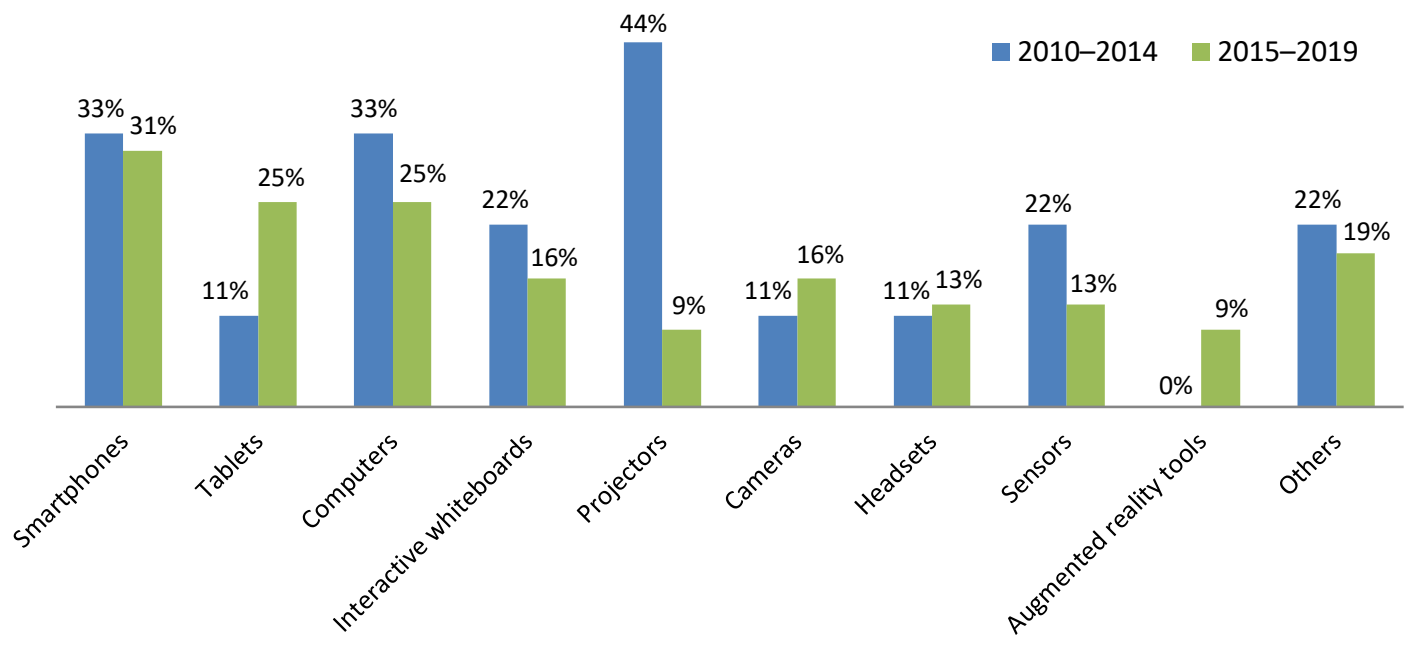

Figure 11. Smart learning devices or tools reported in the literature

\section{Smart learning environments}

Figure 12 illustrates the proportion of smart learning environments that were studied in the two periods. In the first period, the classroom and online environments were the two major smart learning environments, both contributing $44 \%$ of the studies. In the second period, the classroom still had the largest proportion of studies (41\%). However, the proportion of the online environment reduced by $16 \%$, while that of the blended environment increased by $10 \%$. Also, other environments emerged in this period, such as the laboratory and kitchen. The results show that more attention has been paid to implementing smart learning in different environments.

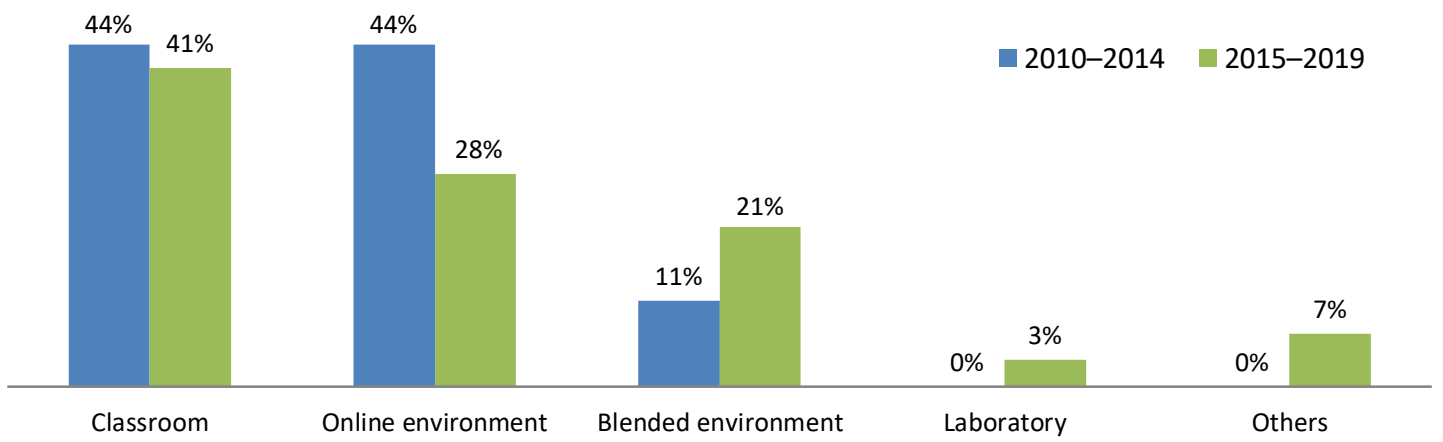

Figure 12. Smart learning environments reported in the literature

\section{Smart learning features}

Figure 13 presents the features of smart learning initiatives reported in the literature. In the first period, the most frequently reported features were context-awareness, personalised content and facilitation of interaction. These three features were emphasised less in the second period, with more attention being paid to adaptivity and collaborative learning. In addition, many more features of smart learning emerged in the second period, such as self-regulated learning, experience-based learning and ubiquitous learning. 


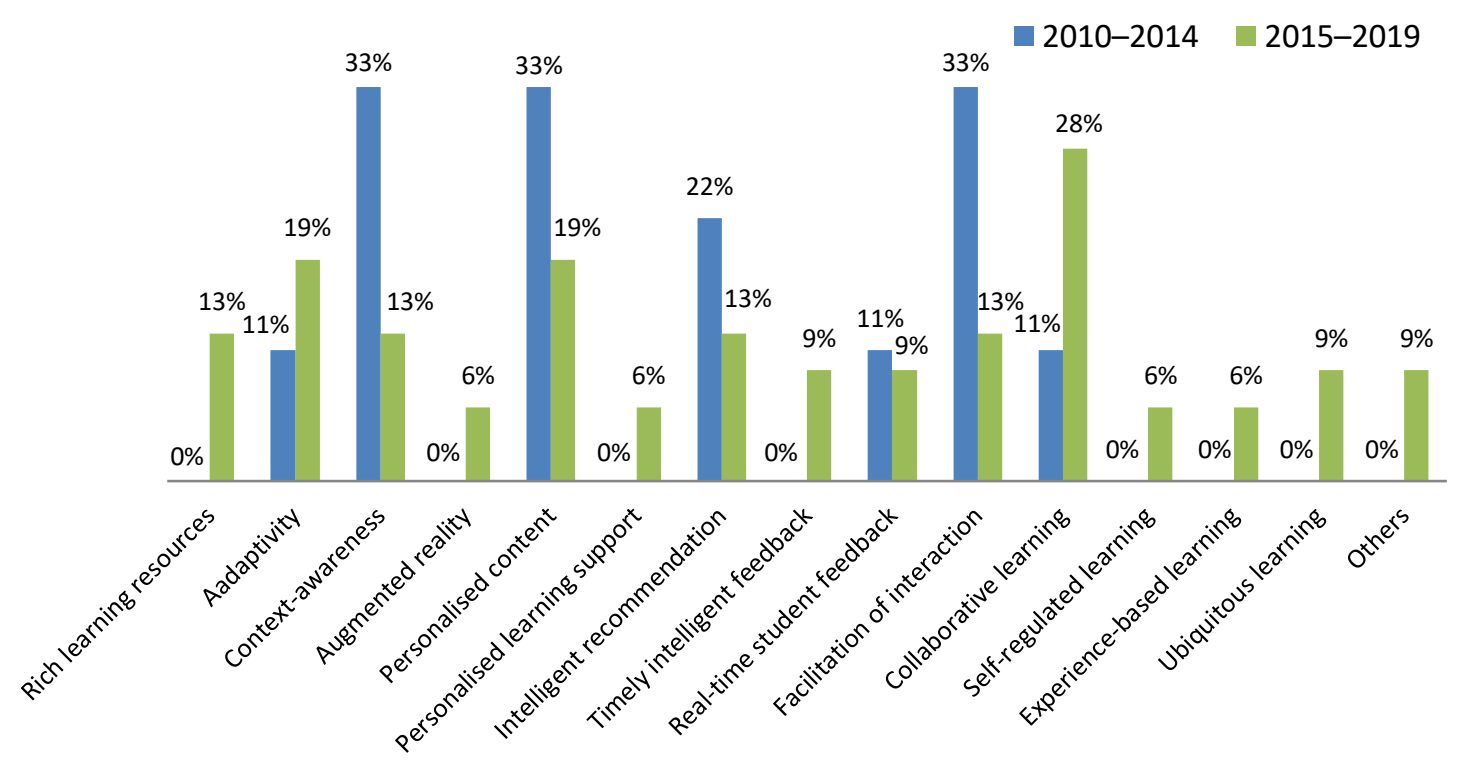

Figure 13. Smart learning features reported in the literature

\section{Discussion}

The findings of this literature review provide a comprehensive overview of smart learning. They supplement previous reviews which focused on more specific aspects of this area. The findings also address the research questions for this review, covering the patterns and trends of smart learning publications, research and practice.

In terms of the publications reviewed, the countries or regions of studies reveal the patterns of global development of smart learning. Relevant work has been more common in Asian and European countries or regions. It is notable that countries such as South Korea have devoted substantial effort and resources in promoting smart learning at the national level (Budhrani et al., 2018), and a wide range of initiatives have been conducted in areas such as conceptual frameworks (Ministry of Education, Science and Technology \& Korea Education and Research Information Service, 2012), smart schools (Hyun, 2015) and teacher development (Ha \& Lee, 2019). They have demonstrated potential ways to support smart learning development and the challenges to tackle.

The research purposes in the literature on smart learning showed that the most popular work lay in developing smart learning systems or tools, but very few studies have attempted to design pedagogies and learning activities for smart learning. This reveals a potential problem for smart learning development namely that most attention has been paid to technological solutions. As Daniela (2019) pointed out, the promise of smart learning technologies, where learners "[have] the possibility to learn at [their] own pace and learn what is needed at any moment", may "diminish the role of pedagogy" (p. vii). However, "the reverse is true ... the role of pedagogy becomes more important because there is an urgent need to find ways to teach and to support learning in the transformed learning environment" (p. viii). Similar views have been raised to highlight the future perspectives of smart learning environments, including pedagogical innovations (Kinshuk et al., 2016). Future work should therefore address to a greater extent how advances in smart learning technologies can be effectively utilised in teaching and learning activities.

The finding that most of the smart learning studies have adopted quantitative research methods is also reflected in related reviews on educational technology (e.g., Baydas et al., 2015; Kucuk et al., 2013). Bond et al. (2020) explained this pattern as being a result of the majority of studies focusing on testing the effects of new ideas, hypotheses and technologies. In addition, Baydas et al. pointed out that the results from quantitative studies can be generalised and made relevant to a wide population. These factors have also been shown in the types of research purposes in smart learning studies, many of which have focused on developing and evaluating the new systems and tools, as discussed above. The limited number of qualitative studies in this area suggests the need to have more in-depth investigations into the issues which have seldom 
been addressed, such as tracing teachers' and students' engagement in smart learning and observing the transformation in teaching and learning behaviours.

The research participants in the smart learning studies were mostly students in both periods. This reflects the focus of smart learning on making learning more effective, efficient and interesting for students (Singh $\&$ Miah, 2020). The results on research purposes and research issues have also shown the emphasis on students' feedback and learning outcomes for smart learning initiatives. Teachers, another major stakeholder group, were covered in only $17 \%$ and $14 \%$ of the studies in the two periods, respectively. The importance of teachers' perspectives has been emphasised by Daniela (2019) and Borawska-Kalbarczyk et al. (2019), in that there is a need for teachers to change their role and further develop their pedagogical competence in smart learning practices. More attention should be paid to the proper role of teachers and the support they need.

There has been a clear trend of diversification in terms of the educational levels of studies, application domains and smart learning environments. The studies have covered various educational levels in a more balanced manner. Likewise, new application domains (e.g., engineering, social studies and physical education) and smart learning environments (e.g., the laboratory and kitchen) have emerged in the second period. It is expected that further developments in smart learning will continue to broaden its contexts of application. In this regard, the diverse conceptualisations of smart learning (Budhrani et al., 2018; Spector, 2014) would be a potential challenge, and future work should be devoted to consolidating relevant conceptual elements as a guiding reference for implementing smart learning in new contexts.

The results show the emerging trends of the features of smart learning reported in the literature, such as collaborative learning, adaptivity, self-regulated learning, experience-based learning and ubiquitous learning. Such features are not unique to smart learning but are highly interrelated with that widely shown in other technology-enhanced learning approaches such as personalised learning (Li \& Wong, 2019a) and mobile learning (Li \& Wong, 2019b). Although it is common for educational practices to incorporate various approaches, the interrelationship between smart learning and other related approaches theoretically, conceptually, methodologically and empirically - should be an important area for future investigation.

The use of smart learning devices or tools in the two periods reveals the impact of technological advances in practice. Some teaching devices, such as projectors, seem to have gradually become obsolete. On the other hand, there has been a growing trend towards adopting handy learning devices, with smartphones and tablets being the most frequently used types of smart learning devices, as well as the emerging use of augmented reality tools. In other words, the notion and scope of smart learning devices have evolved rapidly. It is thus important to keep abreast of such developments and the readiness of smart learning stakeholders (e.g., learners and teachers) to adopt them, which has been found to be highly relevant for the success of implementation (Jemni \& Khribi, 2017; Lee \& Lee, 2015).

In interpreting the results of this study, its limitations should be taken into account. This review has presented an overview of the development of smart learning based on a representative sample of the relevant literature. However, it did not focus on specific areas and technologies of smart learning, which have been covered in other related reviews (e.g., Kearney et al., 2019; Saini \& Goel, 2019; Yoo et al., 2015). Also, while smart learning is at a relatively new stage of development, the number of studies has been small, particularly in the first period (2010-2014). There has been limited data for a more in-depth analysis, such as the disciplinary differences and long-term effects of smart learning practices. Further reviews which cover more of the literature should be carried out in future investigations.

\section{Recommendations for future work}

The findings of the review study also contribute to revealing the areas which have not yet been adequately addressed in the literature. The following are possible areas for future work in the development of smart learning:

- Pedagogical design of smart learning: The small number of studies focusing on designing pedagogies or learning activities for smart learning highlights the need to devote more effort in this area. Changes and innovations in pedagogy are vital for the success of smart learning (Gros, 
2016; Kinshuk et al., 2016; Zhu et al., 2016). Future work in this area should include the design and development of pedagogies which make effective use of smart learning technologies in different learning environments to achieve learning goals. For example, potential studies could examine the new teaching and learning activities enabled in smart classroom environments, and how smart learning technologies could support the design and delivery of hybrid and flexible courses which combine both online and face-to-face environments, as well as students' motivation and satisfaction in them.

- Smart learning for informal learning: The findings of this review show that most of the smart learning studies were conducted in formal (physical or virtual) classroom settings and formal education (i.e., primary, secondary and tertiary education). While smart learning also features ubiquity, it has great potential for application in informal learning contexts such as workplace training, where relevant initiatives have started to emerge. Due to the advances in smart learning technologies, Kinshuk et al. (2016) have envisaged that "the ratio of informal learning to formal learning is only going to increase in the future" (p. 577). Further studies should explore to a greater extent the learning needs of learners in informal contexts as well as examine how smart learning could address their needs and help them cope with the learning contexts.

- Smart learning in different application domains: There has been a trend for smart learning practised in a wider range of application domains. In addition to continuing to expand the use of smart learning in domains which have not been attempted in previous studies (e.g., business and management, arts and design), it is also worth carrying out a more in-depth analysis to examine how smart learning practices have been tailored to fit the characteristics of various application domains, such as language, sciences and computer studies.

- More focus on the teachers' perspective: The majority of research participants in the smart learning studies were students. Although students' views and experiences in smart learning are of the utmost importance, there should be more studies on the perspectives of teachers, another major stakeholder group. Relevant work may include investigation of teachers' views on, perceptions of, and readiness for using smart learning technologies, the challenges they face and their need for support. Potential attributes for study could include their perceived role in smart learning practices and self-efficacy in and barriers to the effective use of specific smart learning technologies.

\section{References}

Baydas, O., Kucuk, S., Yilmaz, R. M., Aydemir, M., \& Goktas, Y. (2015). Educational technology research trends from 2002 to 2014. Scientometrics, 105(1), 709-725. https://doi.org/10.1007/s11192015-1693-4

Bond, M., Buntins, K., Bedenlier, S., Zawacki-Richter, O., \& Kerres, M. (2020). Mapping research in student engagement and educational technology in higher education: A systematic evidence map. International Journal of Educational Technology in Higher Education, 17, Article 2. https://doi.org/10.1186/s41239-019-0176-8

Borawska-Kalbarczyk, K., Tołwińska, B., \& Korzeniecka-Bondar, A. (2019). From smart teaching to smart learning in the fast-changing digital world. In L. Daniela (Ed.), Didactics of smart pedagogy: Smart pedagogy for technology enhanced learning (pp. 23-39). Springer. https://doi.org/10.1007/9783-030-01551-0_2

Budhrani, K., Ji, Y., \& Lim, J. H. (2018). Unpacking conceptual elements of smart learning in the Korean scholarly discourse. Smart Learning Environments, 5, Article 23. https://doi.org/10.1186/s40561-0180069-7

Cebrian, G., Palau, R., \& Mogas, J. (2020). The smart classroom as a means to the development of ESD methodologies. Sustainability, 12(7), Article 3010. https://doi.org/10.3390/su12073010

Chen, C. L. D., Chang, Y. H., Chien, Y. T., Tijus, C., \& Chang, C. Y. (2015). Incorporating a smart classroom 2.0 Speech-Driven PowerPoint System (SDPPT) into university teaching. Smart Learning Environments, 2, Article 7. https://doi.org/10.1186/s40561-015-0010-2

Choi, W., Yeo, I. S., \& Ko, D. S. (2016). Research on strategic implementation of blended smart-learning in tennis using analytic network process. Information, 19(2), 405-411. http://www.informationiii.org/PDF/1902/1902-09.pdf

Daniela, L. (Ed.). (2019). Didactics of smart pedagogy: Smart pedagogy for technology enhanced learning. Springer. https://doi.org/10.1007/978-3-030-01551-0 
Gros, B. (2016). The design of smart educational environments. Smart Learning Environments, 3, Article 15. https://doi.org/10.1186/s40561-016-0039-x

Ha, I., \& Kim, C. (2014). The research trends and the effectiveness of smart learning. International Journal of Distributed Sensor Networks, 10(5). https://doi.org/10.1155\%2F2014\%2F537346

Ha, C. \& Lee, S. Y. (2019). Elementary teachers' beliefs and perspectives related to smart learning in South Korea. Smart Learning Environments, 6, Article 3. https://doi.org/10.1186/s40561-019-0082-5

Heinemann, C., \& Uskov, V. L. (2018). Smart university: Literature review and creative analysis. In V. L. Uskov, J. P. Bakken, R. J. Howlett, \& L. C. Jain (Eds.), Smart universities: Concepts, systems, and technologies (pp. 11-46). Springer. https://doi.org/10.1007/978-3-319-59454-5_2

Hsu, Y. C., Ho, H. N. J., Tsai, C. C., Hwang, G. J., Chu, H. C., Wang, C. Y., \& Chen, N. S. (2012). Research trends in technology-based learning from 2000 to 2009: A content analysis of publications in selected journals. Educational Technology \& Society, 15(2), 354-370. https://www.jstor.org/stable/jeductechsoci.15.2.354

Huh, K. (2018). Key factors of smart learning environments for language classrooms. Indian Journal of Public Health Research and Development, 9(8), 646-650. https://doi.org/10.5958/09765506.2018.00806.9

Huh, K., \& Lee, J. (2020). Fostering creativity and language skills of foreign language learners through SMART learning environments: Evidence from fifth-grade Korean EFL learners. TESOL Journal, 11(2), Article e489. https://doi.org/10.1002/tesj.489

Hwang, G. J. (2014). Definition, framework and research issues of smart learning environments - a context-aware ubiquitous learning perspective. Smart Learning Environments, 1, Article 4. https://doi.org/10.1186/s40561-014-0004-5

Hwang, J. H., \& Choi, H. J. (2016). Influence of smart devices on the cognition and interest of underprivileged students in smart education. Indian Journal of Science and Technology, 9(44), 1-4. https://doi.org/10.17485/ijst/2016/v9i44/105171

Hyun, P. (2015, April 24). Forefront of smart education, Sejong. Korea.net. http://www.korea.net/NewsFocus/Sci-Tech/view?articleId=127152

Jemni, M. \& Khribi, M. K. (2017). The ALECSO Smart Learning Framework. In E. Popescu, Kinshuk, M. K. Khribi, R. Huang, M. Jemni, N. S. Chen, \& D. G. Sampson (Eds.), Innovations in smart learning (pp. 91-101). Springer. https://doi.org/10.1007/978-981-10-2419-1_14

Kassab, M., \& Mazzara, M. (2020). Towards designing smart learning environments with IoT. In J. M. Bruel, M. Mazzara, \& B. Meyer (Eds.), Software engineering aspects of continuous development and new paradigms of software production and deployment (pp. 152-166). Springer. https://doi.org/10.1007/978-3-030-39306-9 11

Kearney, M., Burden, K., \& Schuck, S. (2019). Disrupting education using smart mobile pedagogies. In L. Daniela (Ed.), Didactics of smart pedagogy: Smart pedagogy for technology enhanced learning (pp. 139-157). Springer. https://doi.org/10.1007/978-3-030-01551-0_7

Kinshuk, Chen, N. S., Cheng, I. L., \& Chew, S. W. (2016). Evolution is not enough: Revolutionizing current learning environments to smart learning environments. International Journal of Artificial Intelligence in Education, 26(2), 561-581. https://doi.org/10.1007/s40593-016-0108-X

Kucuk, S., Aydemir, M., Yildirim, G., Arpacik, O., \& Goktas, Y. (2013). Educational technology research trends in Turkey from 1990 to 2011. Computers \& Education, 68, 42-50. https://doi.org/10.1016/j.compedu.2013.04.016

Lee, S. Y., \& Lee, Y. (2015). Analysis of elementary teachers' readiness for smart learning in Korea. In G. Chen, V. Kumar, Kinshuk, R. Huang, \& S. C. Kong (Eds.), Emerging issues in smart learning (pp. 77-84). Springer. https://doi.org/10.1007/978-3-662-44188-6 10

Li, K. C., \& Wong, B. T. M. (2019a). How learning has been personalised: A review of literature from 2009 to 2018. In S. K. S. Cheung, L. K. Lee, I. Simonova, T. Kozel, \& L. F. Kwok (Eds.), Blended learning: Educational innovation for personalized learning (pp. 72-81). Springer. https://doi.org/10.1007/978-3-030-21562-0_6

Li, K. C., \& Wong, B. T. M. (2019b). Mobile learning in health-related disciplines (2009-2018): A review of case studies with the FRAME model. In S. K. S. Cheung, J. Jiao, L. K. Lee, X. Zhang, K. C. Li, \& Z. Zhan (Eds.), Technology in education: Pedagogical innovations (pp. 191-202). Springer. https://doi.org/10.1007/978-981-13-9895-7_17

Li, K. C., \& Wong, B. T. M. (2020a). The use of student response systems with learning analytics: A review of case studies (2008-2017). International Journal of Mobile Learning and Organisation, 14(1), 6379. https://doi.org/10.1504/IJMLO.2020.103901 
Li, K. C., \& Wong, B. T. M. (2020b). Trends of learning analytics in STE(A)M education: A review of case studies. Interactive Technology and Smart Education, 17(3), 323-335. https://doi.org/10.1108/ITSE-11-2019-0073

Liu, D., Huang, R., \& Wosinski, M. (2016). Multicultural perspective on smart learning in smart cities. In D. Liu, R. Huang, \& M. Wosinski (Eds.), Smart learning in smart cities (pp. 217-232). Springer. https://doi.org/10.1007/978-981-10-4343-7_9

Lui, M., \& Slotta, J. D. (2014). Immersive simulations for smart classrooms: Exploring evolutionary concepts in secondary science. Technology, Pedagogy and Education, 23(1), 57-80. https://doi.org/10.1080/1475939X.2013.838452

MacLeod, J., Yang, H. H., Zhu, S., \& Li, Y. (2018). Understanding students' preferences toward the smart classroom learning environment: Development and validation of an instrument. Computers \& Education, 122, 80-91. https://doi.org/10.1016/j.compedu.2018.03.015

Mahesh, G., Jayahari, K. R., \& Bijlani, K. (2016). A smart phone integrated smart classroom. In K. AlBegain (Ed.), Proceedings of the 10th International Conference on Next Generation Mobile Applications, Services, and Technologies (pp. 88-93). The Institute of Electrical and Electronics Engineers. https://doi.org/10.1109/NGMAST.2016.31

Malik, A., Heyman-Schrum, C., \& Johri, A. (2019). Use of Twitter across educational settings: A review of the literature. International Journal of Educational Technology in Higher Education, 16, Article 36. https://doi.org/10.1186/s41239-019-0166-x

McMillan, J. H., \& Schumacher, S. (2006). Research in education: Evidence-based inquiry. Pearson.

Ministry of Education, Science and Technology, \& Korea Education and Research Information Service. (2012). Adapting education to the information age (White Paper). Korea Education and Research Information Service (KERIS). https://asemlllhub.org/wpcontent/uploads/attachments/Republic of Korea - Adapting education to the information age.pdf

Rao, T. V. (2019). A review on awareness of smart learning resources for the improvement of students in mechanical engineering. International Journal of Mechanical Engineering and Technology, 10(1), 242-247.

http://www.iaeme.com/MasterAdmin/Journal_uploads/IJMET/VOLUME_10_ISSUE_1/IJMET_10_0 1 024.pdf

Şahin, M., \& Yurdugül, H. (2019). An intervention engine design and development based on learning analytics: The intelligent intervention system $\left(\operatorname{In}^{2} \mathrm{~S}\right)$. Smart Learning Environments, 6, Article 18. https://doi.org/10.1186/s40561-019-0100-7

Saini, M. K., \& Goel, N. (2019). How smart are smart classrooms? A review of smart classroom technologies. ACM Computing Surveys, 52(6), Article 130. https://doi.org/10.1145/3365757

Singh, H., \& Miah, S. J. (2020). Smart education literature: A theoretical analysis. Education and Information Technologies, 25, 3299-3328. https://doi.org/10.1007/s10639-020-10116-4

Spector, J. M. (2014). Conceptualizing the emerging field of smart learning environments. Smart Learning Environments, 1, Article 2. https://doi.org/10.1186/s40561-014-0002-7

Suwita, J., Kosala, R., Ranti, B., \& Supangkat, S. H. (2019). Factors considered for the success of the massive open online course in the era of smart education: Systematic literature review. In S. H. Supangkat, J. Sembiring, A. A. Arman, IGB B. Nugraha, \& Y. Bandung (Eds.), Proceedings of the 2019 International Conference on ICT for Smart Society (pp. 79-83). IEEE. https://doi.org/10.1109/ICISS48059.2019.8969844

Tu, Y. F., \& Hwang, G. J. (2018). Trends of library-associated mobile learning based on a review of academic studies published from 2007 to 2016. The Electronic Library, 36(5), 875-891. https://doi.org/10.1108/EL-06-2017-0138

Vasbieva, D. G., Sokolova, N. L., Masalimova, A. R., Shinkaruk, V. M., \& Kiva-Khamzina, Y. L. (2018). Exploring EFL teacher's role in a smart learning environment-review study. XLinguae, 11(2), 265274. http://www.xlinguae.eu/files/XLinguae2 2018 21.pdf

Vesin, B., Mangaroska, K., \& Giannakos, M. (2018). Learning in smart environments: user-centered design and analytics of an adaptive learning system. Smart Learning Environments, 5, Article 24. https://doi.org/10.1186/s40561-018-0071-0

Vlachopoulos, D. \& Makri, A. (2017). The effect of games and simulations on higher education: A systematic literature review. International Journal of Educational Technology in Higher Education, 14, Article 22. https://doi.org/10.1186/s41239-017-0062-1

Wong, B. T. M., Li, K. C., \& Choi, S. P. M. (2018). Trends in learning analytics practices: A review of higher education institutions. Interactive Technology and Smart Education, 15(2), 132-154. https://doi.org/10.1108/ITSE-12-2017-0065 
Yoo, Y., Lee, H., Jo, I.-H., \& Park, Y. (2015). Educational dashboards for smart learning: Review of case studies. In G. Chen, V. Kumar, Kinshuk, R. Huang, \& S. C. Kong (Eds.), Emerging issues in smart learning (pp. 145-155). Springer. https://doi.org/10.1007/978-3-662-44188-6_21

Zhu, Z. T., Yu, M. H., \& Riezebos, P. (2016). A research framework of smart education. Smart Learning Environments, 3, Article 4. https://doi.org/10.1186/s40561-016-0026-2

Corresponding author: Billy Tak-Ming Wong, tamiwong@ouhk.edu.hk

Copyright: Articles published in the Australasian Journal of Educational Technology (AJET) are available under Creative Commons Attribution Non-Commercial No Derivatives Licence (CC BY-NC-ND 4.0). Authors retain copyright in their work and grant AJET right of first publication under CC BY-NC-ND 4.0.

Please cite as: Li, K. C., \& Wong, B. T. M. (2021). Review of smart learning: Patterns and trends in research and practice. Australasian Journal of Educational Technology, 37(2), 189-204. https://doi.org/10.14742/ajet.6617 